\title{
One-trial simultaneous and backward excitatory fear conditioning in rats: Lick suppression, freezing, and rearing to CS compounds and their elements
}

\author{
MELODY ALBERT and JOHN J. B. AYRES \\ University of Massachusetts, Amherst, Massachusetts
}

\begin{abstract}
Three experiments with rat subjects sought to enhance one-trial excitatory simultaneous and backward fear conditioning by using a two-element compound conditioned stimulus (CS) instead of only a single element. During conditioning, experimental groups received a 4-sec CS either coextensively with a 1-mA grid-shock unconditioned stimulus (US) or immediately after US termination. In subsequent tests, CSs evoked more lick suppression and freezing in these groups than in various controls. Compound CSs evoked more lick suppression and freezing than did CS elements, but did so equally for experimental and control groups. Therefore, the use of compounds did not enhance conditioning. Unexpectedly, an explicitly unpaired control in which CS followed US termination by 3 min tended to show more CS-evoked suppression and freezing than did a control in which CS preceded US onset by $3 \mathrm{~min}$. This result raises the possibility that associations between the CS and the training context might engender responding to backward-paired CSs.
\end{abstract}

In a well-known review of the literature on backward excitatory conditioning, Spetch, Wilkie, and Pinel (1981) concluded that "the time for disputing whether backward conditioning is possible is past; it is time, instead, for systematic exploration of the conditions under which it occurs and the variables that affect the magnitude and duration of the effect" (p. 174).

Since 1981, however, no parametric studies of either backward or simultaneous conditioning have, to our knowledge, been published. An impediment to such parametric work is that excitatory backward and simultaneous conditioning phenomena are not robust. Indeed, recent work has failed to find evidence for either simultaneous or backward conditioning unless indirect measures were used (Barnet, Arnold, \& Miller, 1991; Matzel, Held, \& Miller, 1988). These indirect measures involved assessing the ability of the simultaneous or backward CS to support either second-order conditioning or sensory preconditioning to some other CS. Similarly, other work (Gordon, McGinnis, \& Weaver, 1985) found no evidence for exci-

This research is based on a doctoral dissertation submitted by the first author to the Graduate School of the University of Massachusetts, Amherst in 1990, in partial fulfillment of the requirements for the $\mathrm{PhD}$ degree. We thank the members of the dissertation committee: John W. Donahoe, Melinda A. Novak, and Gordon A. Wyse. The work was supported by Grant BNS 87-22173 from the National Science Foundation. Preparation of the manuscript was supported by Grant MH50491 from the National Institute of Mental Health. Both grants were awarded to J.J.B.A. Correspondence may be addressed to either author. M. Albert is now at the Department of Psychology, Concordia College, 901 South Eighth Street, Moorhead, MN 56560 . J. J. B. Ayres's address is Department of Psychology, University of Massachusetts, Amherst, MA 01003 (e-mail: joeayres@psych.umass.edu). tatory backward conditioning unless special "reminder" treatments were used prior to testing for conditioning.

In our own laboratory, unpublished parametric analyses of one-trial backward excitatory conditioning (as assessed by direct measures of the behavior evoked by the backward CS itself) have been frustrated by occasional failures to find such conditioning when we changed our previously successful procedures slightly (Ayres, Haddad, \& Albert, 1987; Mahoney \& Ayres, 1976; Shurtleff \& Ayres, 1981; van Willigen, Emmett, Cote, \& Ayres, 1987).

One aim of the present research was to explore a technique that might yield more robust simultaneous and backward excitatory conditioning than yet described. To this end, we compared the conditioned responses (CRs) evoked by conditioned stimulus (CS) compounds with those evoked by single elements of those compounds. This strategy was suggested by the well-known Pavlovian conditioning model of Rescorla and Wagner (1972). That model assumes that on the first trial of compound conditioning, each CS element gains as much conditioned value as if reinforced in isolation. The model also assumes that the conditioned value of a compound is simply the sum of the values of its constituent elements. From these two assumptions, it follows that, after only a single conditioning trial, the learned value of a compound CS must exceed the value of either of its elements. We thus hoped to find stronger one-trial excitatory simultaneous and backward conditioning to compounds than to elements, a finding that might be exploited in future parametric analyses of simultaneous and backward conditioning. Note that in focusing on a CS variable, we expressly avoided the obvious option of increasing unconditioned stimulus (US) intensity and/or duration. We did so because our test pro- 
cedures involve superimposing CSs upon an appetitive baseline (licking a sipper tube) and taking the CS-evoked suppression of that baseline as an index of conditioning. We feared that increasing the US intensity beyond values used before might damage that baseline and, hence, our ability to assess the effects of CSs.

A second aim of the research was to examine in some detail the conditioned defensive behaviors evoked by various CSs. In multitrial forward-conditioning procedures, auditory CSs often evoke more conditioned freezing (defensive immobility) than do visual CSs (Ayres, Axelrod, Mercker, Muchnik, \& Vigorito, 1985; Bevins \& Ayres, 1991, 1992c; Helmstetter \& Fanselow, 1989; Sigmundi \& Bolles, 1983; Sigmundi, Bouton, \& Bolles, 1980), and similar results have been reported for one-trial forward conditioning (van Willigen et al., 1987). The present work provided a chance to look for similar differences in onetrial simultaneous and backward procedures. We studied simultaneous conditioning in Experiments 1 and 2 and backward conditioning in Experiment 3.

\section{EXPERIMENT 1}

In Experiment 1, four conditioning treatments were crossed in a factorial design with three test treatments. The four conditioning treatments were termed $\mathrm{T}+, \mathrm{L}+$, TL+, and SIT, referring, respectively, to simultaneous presentation of tone and shock, light and shock, tone + light and shock, and exposure to the conditioning context only. The three test conditions were termed T, L, and $T L$, referring, respectively, to a test presentation of the tone, light, or tone+light compound.

Van Willigen et al. (1987) found no evidence for onetrial backward excitatory conditioning to a light CS and had difficulty in showing one-trial forward conditioning to that CS. Because their light CS did not flash, and because prior work (e.g., Gormezano, 1972) had suggested that pulsing CSs support stronger CRs than do constant ones, we chose to use a flashing light CS here.

\section{Method}

Subjects. The subjects were 107 male albino rats, about 90 days old on arrival from the Holtzman Company, Madison, WI. They lived singly in stainless steel cages in a room lighted $24 \mathrm{~h} /$ day and had free access to laboratory rat chow (laboratory rodent diet 5001 from PMI Feeds, Inc.) throughout the experiment. They were deprived of water on a 23.5 -h schedule imposed 2 days before training began.

Apparatus. A single conditioning/test box was housed in a ventilated $.61-\mathrm{m}$ cube of $12.7-\mathrm{mm}$ plywood lined with acoustical tile. The inside dimensions of the box were $23.2 \times 20.3 \times 19.5 \mathrm{~cm}$. The floor was made of eighteen $2-\mathrm{mm}$ stainless steel rods, mounted $1.3 \mathrm{~cm}$ apart. The two end walls were aluminum. The sidewalls and lid were Plexiglas. One of the sidewalls faced the Plexiglas door on the front of the housing cube, permitting direct observation of the rat's behavior. A horizontal slot $(5.1 \times 1.3 \mathrm{~cm})$, centered in this wall and located $4.5 \mathrm{~cm}$ above the floor, revealed a sipper tube attached to a bottle of tap water. The standard position of the tube was $1 \mathrm{~mm}$ outside the box with the top half of the tube above the top of the slot. This position prevented all but tongue contacts. The tube was wired to a Grason-Stadler drinkometer (Model E3690A-1) that sensed licks.
A tone $\mathrm{CS}(1000 \mathrm{~Hz}$ at $86-\mathrm{dB}[\mathrm{C}])$ was produced by an Exar Precision Waveform Generator (XR-8038/8038A). The tone was played through a speaker $(10 \mathrm{~cm}$ diam) mounted on the box lid. The background noise level, mainly from an exhaust fan, was $62 \mathrm{~dB}(\mathrm{C})$. A flashing-light CS was provided by two frosted white bulbs $(7.5 \mathrm{~W}$ at $110 \mathrm{~V}$ ). One was mounted on the rear wall of the housing cube, $24 \mathrm{~cm}$ above its floor and $15 \mathrm{~cm}$ from the nearest Plexiglas wall of the box. The second bulb was mounted on the floor of the housing cube and was placed $8 \mathrm{~cm}$ in front of the sipper-tube slot. The two bulbs produced a reading of $200 \mathrm{~lx}$ on a Pasco Scientific photometer with its selenium cell near the sipper tube. A red bulb $(25 \mathrm{~W}$ at $110 \mathrm{~V})$, mounted on the rear wall of the housing cube and located $10 \mathrm{~cm}$ directly above the white bulb, provided background lighting. It produced a reading of $2 \mathrm{~lx}$. A high-voltage shock source with a relay-sequencing scrambler (Hoffman \& Fleshler, 1962) applied a shock US ( $1 \mathrm{~mA}$ for $4 \mathrm{sec}$ ) through the grid floor.

A Panasonic video camera (PK-959), able to operate under low light, was used to film behavior. Recording was done with a JVC videocassette recorder (HR-D142U). A personal computer (NCR 6) controlled experimental events and recorded licks.

Procedure. On Days 1-4, each rat was placed alone in the box and allowed to lick the sipper tube. On Day 1 only, the tube extended $5 \mathrm{~mm}$ into the box so that the rat could find it quickly. On the rat's 100 th lick, a 2-min dummy CS (no detectable stimulus change) was presented. The time between the 90th and 100th licks (dummy pre-CS time) and the time between the 100th and 110th licks (dummy CS time) served as dependent measures. Two minutes after the dummy CS ended, the rat was returned to its home cage and given free access to water for $30 \mathrm{~min}$.

Following lick training, the rats were assigned to the 12 cells of a $4 \times 3$ factorial design. The groups were matched in terms of their dummy pre-CS and CS times on Day 4. The experiment was performed in four replications with roughly equal numbers of rats from each group placed in each replication. ${ }^{1}$ There were 8 rats in Group SIT/T and 9 rats in each of the remaining groups. (Throughout this paper, the term before the slash in the group names denotes the conditioning treatment, and the term after the slash denotes the test CS.)

On Day 5 , the water bottle was removed from the box, and all but the rats in the three SIT groups received a single simultaneous fearconditioning trial. It consisted of a shock US ( $1 \mathrm{~mA}$ for $4 \mathrm{sec}$ ) given coextensively with a 4-sec CS. For Groups T+/T, T+/L, and T+/TL, the CS was the tone. For Groups $\mathrm{L}+/ \mathrm{L}, \mathrm{L}+/ \mathrm{T}$, and $\mathrm{L}+/ \mathrm{TL}$, the CS was the flashing white light. For Groups $T L+/ T, T L+/ L$, and $\mathrm{TL}+/ \mathrm{TL}$, the CS was the compound of tone+light. CS and US began $214 \mathrm{sec}$ into a $432-\mathrm{sec}$ session. Groups SIT/T, SIT/L, and SIT/TL sat in the box for $432 \mathrm{sec}$ but received neither CS nor US

On Day 6, the rats were treated as on Days $1-4$, except that a 2min test $\mathrm{CS}$ replaced the dummy $\mathrm{CS}$. For Groups $\mathrm{T}+/ \mathrm{T}, \mathrm{L}+/ \mathrm{T}$, and $\mathrm{TL}+/ \mathrm{T}$, the test $\mathrm{CS}$ was the tone. For Groups $\mathrm{T}+/ \mathrm{L}, \mathrm{L}+/ \mathrm{L}$, and $\mathrm{TL}+/ \mathrm{L}$, the test CS was the flashing light. For Groups $T+/ T L, L+/ T L$, and $\mathrm{TL}+/ \mathrm{TL}$, the test $\mathrm{CS}$ was the tone+light compound. The latency to emit 10 licks in CS presence was recorded and is termed the CS10 time. That measure is the index of conditioned lick suppression used by Mahoney and Ayres (1976). The latency to 25 licks in CS presence (CS25 time) was also recorded (cf. Kasprow, Schachtman, \& Miller, 1987). We used both measures so as to assess their relative sensitivity to conditioning. We converted both to logs (base 10) for consistency with other work (cf. van Willigen et al., 1987). Untransformed data are available in Albert (1990). The total number of licks during the 2-min CS was also recorded as well as a cumulative total every $10 \mathrm{sec}$. Rats failing to emit 110 licks by the end of the 2 -min test CS were given a CS time of $120 \mathrm{sec}$. In the $2 \mathrm{~min}$ following CS offset, the computer continued to record the time to the 110 th lick (total suppression time). Rats failing to make 110 licks by the end of this added period were assigned a total suppression time of $240 \mathrm{sec}$.

The rats were also filmed during testing. Later, the first author scored the videotapes for freezing, rearing, and licking during the 
CS. Scoring was paced by a 1 -per-second click that was dubbed onto the videotape. Only one of the behaviors was scored at a time. A second observer, naive as to the rats' treatment, independently scored the same behaviors in one randomly selected rat per group. Of the observations scored in common, the 2 observers agreed on $89 \%$ for freezing, $98 \%$ for rearing, and $96 \%$ for licking. Freezing was defined as the absence of any movement except that required to breathe. Rearing was defined as having both forepaws off the floor and the head at least $11.5 \mathrm{~cm}$ above it. Licking was defined as apparent contact between tongue and sipper tube. The videotaped record for the test day was lost for 1 rat in Group $L+/ T$.

\section{Results and Discussion}

If freezing underlies conditioned suppression, then freezing and lick suppression should covary. Indeed, Pearson product moment correlations between log CS10 times and freezing were $.59, .59$, and .69 for L, TL, and T, respectively $(p \mathrm{~s}<.05)$. For this reason, the suppression and freezing data will be described together. Then other behavioral measures will be described.

Lick suppression and freezing. The top panel of Figure 1 shows the mean log pre-CS and CS10 times to the test CS. The bottom panel shows the freezing. The results suggest that there was more suppression and freezing to (1) CSs that had been paired with shock versus CSs that had not, (2) CSs in groups that had received a shock versus CSs in SIT groups, and (3) compounds that had been paired with shock versus elements that had been paired with shock. These summary statements were supported in a series of statistical analyses in which the rejection region was .05 (two-tailsd) unless stated otherwise.

The data from Groups $\mathrm{T}+/ \mathrm{T}, \mathrm{L}+/ \mathrm{T}, \mathrm{L}+/ \mathrm{L}$, and $\mathrm{T}+/ \mathrm{L}$ were subjected to $2 \times 2$, treatment (target or nontarget CS paired) $\times$ test CS (T or L), analyses of variance (ANOVAs) in search of evidence for simultaneous conditioning to a CS element. For the CS10 times, only the main effect of treatment $[F(1,32)=8.67]$ was significant, revealing more suppression in Groups $\mathrm{T}+/ \mathrm{T}$ and $\mathrm{L}+/ \mathrm{L}$ (combined) than in Groups $\mathrm{L}+/ \mathrm{T}$ and $\mathrm{T}+/ \mathrm{L}$ (combined). This result provides evidence for simultaneous conditioning. The lack of a significant treatment $\times \mathrm{CS}$ interaction $(F<1)$ suggests similar conditioned responding to $\mathrm{T}$ and $\mathrm{L}$. The freezing data supported the same conclusions. Only the main effect of treatment was significant $[F(1,31)=4.27]$.

The data from Groups L+/T, SIT/T, T+/L, and SIT/L were subjected to $2 \times 2$, treatment (nontarget CS paired or SIT) $\times$ CS $(\mathrm{T}$ or L), ANOVAs. For the CS10 times, only the main effect of treatment $[F(1,31)=9.41]$ was significant, indicating that Groups $\mathrm{T}+/ \mathrm{L}$ and $\mathrm{L}+/ \mathrm{T}$ (combined) suppressed more than Groups SIT/T and SIT/L (combined). Freezing showed the same pattern. Only the main effect of treatment was significant $[F(1,30)=15.92]$. The greater suppression and freezing in Groups $\mathrm{T}+/ \mathrm{L}$ and $\mathrm{L}+/ \mathrm{T}$ than in the SIT controls could be taken as evidence for either cross-modal generalization or pseudoconditioning. Prior work (Kamin, 1968; van Willigen et al., 1987) has suggested little cross-modal generalization between auditory and visual CSs, so pseudoconditioning seems more likely. Pseudoconditioning refers to a USproduced enhancement of a "CR-like" response to the
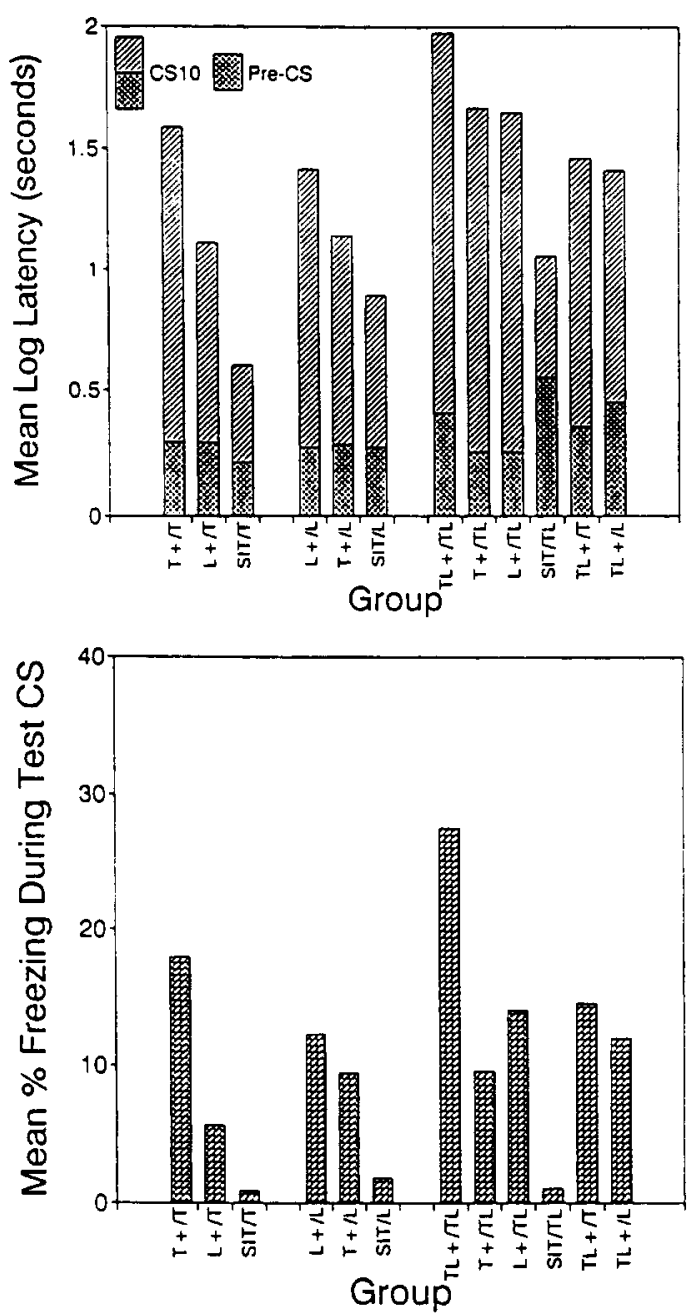

Figure 1. Experiment 1. Top panel: mean log pre-CS times (bottom part of bar) and mean log CS10 times (entire bar) during test CS. Bottom panel: mean percent of observations judged as freezing during test $\mathrm{CS}$.

CS, an enhancement not due to CS-US pairing (Domjan \& Burkhard, 1986).

Simultaneous conditioning to the TL compound is difficult to assess in the present design. A comparison between Group TL+/TL and Group SIT/TL is not conservative enough because it fails to control for pseudoconditioning. Much more conservative is a comparison of Group TL $+/ T L$ and the groups conditioned with only one element but tested with the compound (Groups $\mathrm{T}+/ \mathrm{TL}$ and $\mathrm{L}+/ \mathrm{TL}$ ). That comparison seems too conservative, because one of the elements of the compound in the "control" groups was conditioned. Still, there was evidence for conditioning to the compound: Group TL+/TL suppressed significantly more than did Groups $\mathrm{T}+/ \mathrm{TL}$ and $\mathrm{L}+/ \mathrm{TL}$ combined $[t(25)=2.60]$. Groups $\mathrm{T}+/ \mathrm{TL}$ and $\mathrm{L}+/ \mathrm{TL}$ did not differ $(t<1)$. Group $\mathrm{TL}+/ \mathrm{TL}$ also tended to freeze more than did Groups $\mathrm{T}+/ \mathrm{TL}$ and $\mathrm{L}+/ \mathrm{TL}$ combined $[t(25)=2.01, p=.06$, one-tailed]. Groups $\mathrm{T}+/ \mathrm{TL}$ and $\mathrm{L}+/ \mathrm{TL}$ did not differ $(t<1)$. 
Although there is evidence for simultaneous conditioning to the TL compound, it is unclear whether that conditioning exceeded the conditioning to the $\mathrm{T}$ or $\mathrm{L}$ elements. Group TL $+/ T L$ cannot be directly compared with Group $\mathrm{T}+/ \mathrm{T}$ or with Group $\mathrm{L}+/ \mathrm{L}$ because differences in conditioning are completely confounded with nonassociative differences in the test CSs. Thus, there might be more unconditioned suppression and/or more pseudoconditioning to a compound than to its elements. The contrast of Group $\mathrm{TL}+/ \mathrm{TL}$ versus Groups $\mathrm{T}+/ \mathrm{TL}$ and $\mathrm{L}+/ \mathrm{TL}$ (combined) removes these nonassociative problems because these three groups received the same test CS and the same US. However, Groups T+/TL and L+/TL should suffer generalization decrement when their $\mathrm{CS}$ is changed between conditioning and testing, whereas Group TL+/TL should not. Thus, we cannot reject the hypothesis that $\mathrm{T}$, $\mathrm{L}$, and TL had similar conditioned values in Groups $\mathrm{T}+/ \mathrm{TL}, \mathrm{L}+/ \mathrm{TL}$, and TL+/TL, respectively. Experiment 1 , then, has no proper control procedure to allow us to conclude that conditioning is stronger to a compound than to an element. Such a control should receive the same CS in conditioning and testing as the experimental group but should receive it explicitly unpaired with the US during conditioning. Then we must show that the difference between experimental and control group performance is greater when the CS is a compound than when it is an element. This demonstration requires a significant interaction in an ANOVA in which the variables are treatment (paired or unpaired) and CS type (compound or element). Experiment 2 will use that design.

The differences in lick suppression discussed above were not complicated by differences in baseline lick rates. ANOVAs of log pre-CS times, like those conducted on $\log$ CS10 times, revealed no significant differences among groups (largest $F=1.14$ ).

A number of lick-suppression measures in addition to CS10 time were analyzed (CS25 time; total suppression time, 10 licks; total suppression time, 25 licks; total number of licks during the CS; and number of licks during the first 30 and $60 \mathrm{sec}$ of the test CS). None of these other measures were consistently more sensitive to conditioning than was $\log$ CS10 time. The within-group variability appeared to be greater for the CS25 time than for the CS10 time. For that reason, the results are presented in terms of $\log$ CS10 time.

Other behavioral observations. The videotapes suggested that the rats that received $\mathrm{L}$ or $\mathrm{TL}$ in testing often reared at the start of the CS. Because orienting responses (ORs) to a CS probably occur shortly after CS onset, the first $10 \mathrm{sec}$ of the 2-min test CS on the test day was examined. Figure 2 shows the mean percent of rearing during the $10-\mathrm{sec}$ period. These data suggest that (1) there was more rearing to $L$ than to $T,(2)$ rearing is an OR, not a $C R$, and (3) freezing suppresses rearing. These summary statements were supported in a series of statistical analyses.

A $3 \times 2$, treatment (target CS paired, target CS unpaired, or SIT) $\times$ test CS (T or L), ANOVA was con-

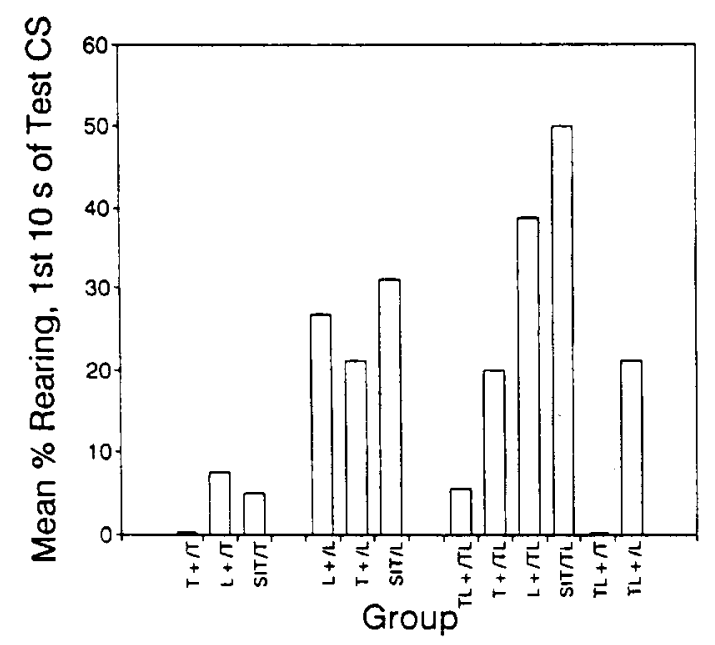

Figure 2. Mean percent of observations judged as rearing during the first $10 \mathrm{sec}$ of the test CS in Experiment 1.

ducted on the rearing scores to see if rearing was greater to $L$ than to $T$. The main effect of CS $[F(1,46)=12.85]$ indicated that it was. No other effects were significant.

Comparisons were made to see if rearing was an OR or a CR to $\mathrm{L}$. This question was of interest because past evidence had suggested that rearing was an OR (Holland, 1979), not a CR (van Willigen et al., 1987), to L. In the present experiment, Group $\mathrm{L}+/ \mathrm{L}$ did not rear more than Group $\mathrm{T}+/ \mathrm{L}(t<1)$, arguing against rearing as a CR to $L$. We might expect that if rearing was an $O R$ to $L$, Group SIT/L would rear more than would Group L+/L. Although this result is suggested by Figure 2, the difference was not significant $(t<1)$.

Comparisons were also made to see if rearing was a $\mathrm{CR}$ or an $\mathrm{OR}$ to the compound. If rearing was a $\mathrm{CR}$, we would expect Group TL+/TL to rear more than Groups $\mathrm{L}+/ \mathrm{TL}$ and $\mathrm{T}+/ \mathrm{TL}$ (pooled). In fact, Group $\mathrm{TL}+/ \mathrm{TL}$ reared significantly less than these groups $[t(25)=2.29$, arguing against rearing as being a CR to the TL compound. Group SIT/TL reared significantly more than Group TL+/TL $[t(16)=6.86]$, providing evidence for rearing as an OR to the compound. Presumably, rearing is evoked mainly by $\mathrm{L}$ in the TL compound, because the comparisons listed above showed that $\mathrm{L}$ evoked more rearing than did T. Group SIT/TL tended to rear more than did Group SIT/L $[t(16)=2.05, p=.06$, one-tailed], suggesting that the small amount of rearing to $T$ might summate with that to $L$ when the two novel cues were compounded.

Some of the comparisons just described also suggest that the CR of freezing acts to suppress the OR of rearing. Consider the groups tested with the TL compound. We should expect most rearing to be in Group SIT/TL because the TL compound was novel. That compound should evoke the OR of rearing with no interference from the CR of freezing. The next most rearing should occur in Groups $T+/ T L$ and $L+/ T L$. For them, one element was novel, evoking rearing, but the other was conditioned, 
evoking freezing. The least rearing should occur in Group TL+/TL because neither element was fully novel and both were conditioned. Any tendency of the elements to evoke the OR of rearing should be overcome by their tendency to evoke the CR of freezing. The data in Figure 2 are clearly consistent with these expectations. If freezing suppresses rearing, we might also expect less rearing in Group L $+/ L$ than in Group SIT/L. Although Figure 2 suggests that this may be true, the difference between the groups was not significant. This is probably because Group $\mathrm{L}+/ \mathrm{L}$ did not freeze much during the first part of the CS, and so L could not strongly suppress rearing. (See discussion below on freezing throughout the 120sec CS in Group L+/L.)

The first author also carefully viewed the videotapes (but without systematic scoring) in an effort to identify a possibly unique defensive behavior to $\mathrm{L}$. This effort was driven by a suggestion made by Ayres et al. (1985). These authors found more freezing to noise than to light but similar barpress suppression. Assuming that suppression is mediated by competing conditioned defensive behaviors, they suggested that $\mathrm{L}$ must evoke some other defensive behavior, incompatible with barpressing, to compensate for the lack of freezing. In the present study, the dominant behavior during the test CS was licking. The rats also engaged in freezing and a number of other behaviors. These other behaviors seemed unlikely to be defensive. They included walking, rearing, grooming, sniffing or biting the grid floor, and extending the paws through the grids as if to handle something in the empty litter tray. If a unique conditioned defensive response to L exists, it would surely be strongest in Group L+/L, for which $\mathrm{L}$ was conditioned. When the behavior of this group was examined, about $44 \%$ of the observations were scored as licking, $9 \%$ as rearing, $12 \%$ as freezing, and $35 \%$ as other. It is tempting to speculate that the unique defensive behavior to $\mathrm{L}$ is included in the $35 \%$ of the behavior classified as other, yet a behavior that seemed defensive did not emerge. The rats, for example, did not paw at the floor, walls, or lid of the box as if trying to escape. They did not move to a certain part of the box as if trying to withdraw from $\mathrm{L}$.

Fanselow and Lester (1988) also tried to find evidence for defensive behavior other than freezing to $\mathrm{L}$, as we did. In three geometrically different contexts, they observed rats that had received 12 pairings of a flashing-light CS and a grid-shock US. They found that the behavior evoked by the light was freezing, regardless of the context. They note that "if the animals were making any specific response other than freezing we were there to observe it. Yet we never observed such a response" (p. 198).

Although the defensive behaviors to $\mathrm{T}$ and $\mathrm{L}$ do not appear to differ in kind, they might differ in duration. For example, $\mathrm{T}$ might evoke a few long bouts of freezing, whereas L might evoke a larger number of short bouts. However, we found no support for this idea. The mean length of a freezing bout during the test CS for Groups $\mathrm{T}+/ \mathrm{T}$ and $\mathrm{L}+/ \mathrm{L}$ was 1.64 and $1.63 \mathrm{sec}$, respectively $(t<1)$.

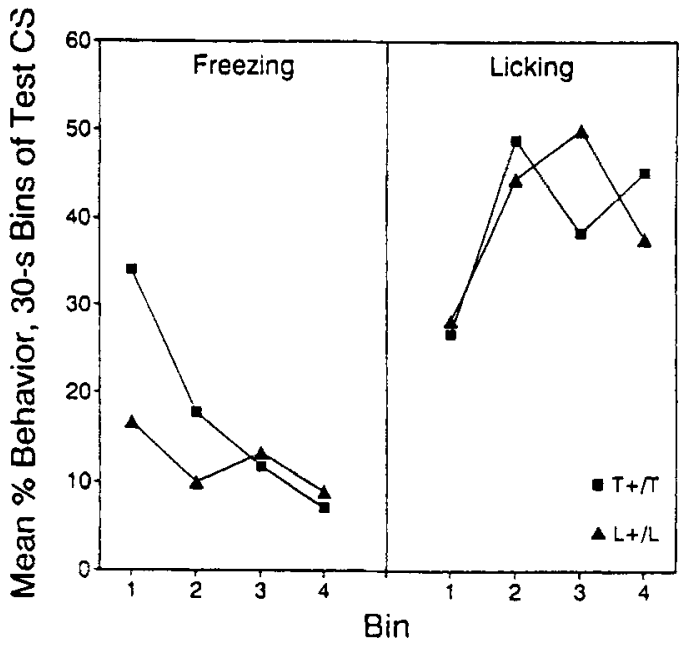

Figure 3. Mean percent of observations judged as freezing (left panel) or licking (right panel) during successive 30 -sec bins in the test CS in Experiment 1.

It is also possible that freezing to $\mathrm{T}$ and $\mathrm{L}$ might differ in distribution throughout the test $\mathrm{CS}$. We did find evidence for that: The percent freezing for Groups $\mathrm{T}+/ \mathrm{T}$ and $\mathrm{L}+/ \mathrm{L}$ during successive $30-\mathrm{sec}$ bins of the test $\mathrm{CS}$ is shown in the left panel of Figure 3. A $2 \times 4$, CS $(\mathrm{T}$ or $\mathrm{L}) \times$ bin (1-4), repeated measures ANOVA was conducted on these data. The main effect of bin $[F(3,48)=8.44]$ indicated that freezing decreased (extinction occurred) across successive $\mathrm{CS}$ bins. The $\mathrm{CS} \times$ bin interaction was significant, meaning that the course of freezing over successive bins differed for $\mathrm{T}$ and $\mathrm{L}[F(3,48)=3.22]$. Group $\mathrm{T}+/ \mathrm{T}$ froze more during the first $30 \mathrm{sec}$ than did Group $\mathrm{L}+/ \mathrm{L}[t(16)=2.37]$. In later bins, freezing in Group $\mathrm{T}+/ \mathrm{T}$ declined to the level of Group $\mathrm{L}+/ \mathrm{L}$. For this reason, the main effect of CS type was not significant. The percent licking for Groups $\mathrm{T}+/ \mathrm{T}$ and $\mathrm{L}+/ \mathrm{L}$ during successive 30 -sec bins of the test CS is shown in the right panel of Figure 3. A $2 \times 4$, CS (T or L) $\times$ bin $(1-4)$, repeated measures ANOVA like that done on the freezing data revealed no significant effects, implying that the course of licking across successive bins was similar for $\mathrm{T}$ and $\mathrm{L}$. This result contrasts with the freezing pattern, and the contrast is consistent with work (e.g., Ayres et al., 1985; Kim, Rivers, Bevins, \& Ayres, 1996) that found similar levels of barpressing to $T$ and $L$, yet more freezing to $\mathrm{T}$ than to $\mathrm{L}$.

In summary, both the lick-suppression and behavioral observation measures provided evidence for simultaneous conditioning to T, $\mathrm{L}$, and TL. The behavioral observations also suggested that (1) freezing was the defensive behavior to both $\mathrm{T}$ and $\mathrm{L}$, (2) rearing was an OR to $\mathrm{L}$, and (3) the rearing OR and the freezing CR were mutually interfering. Experiment 1 permits no strong conclusion about whether a compound yields stronger conditioning than its elements. This issue will be reexamined in Experiment 2. 


\section{EXPERIMENT 2}

Experiment 2 used an explicitly unpaired (EU) procedure as a control for assessing conditioning to both element and compound CSs and for asking if conditioning was stronger to a compound than to its elements. Its design was a $2 \times 5$ factorial with two treatments (paired or EU) crossed with five CSs (tone, light, noise, tone+light, tone+noise). If conditioning were stronger to a compound than to its elements, we would expect a larger difference between experimental and control groups conditioned and tested with a compound than between experimental and control groups conditioned and tested with an element. That outcome would yield a significant interaction between treatment (paired vs. control) and CS type (element vs. compound).

On the basis of the evidence that auditory CSs evoke more freezing than light CSs do (see, e.g., Ayres et al., 1985), we might also expect stronger freezing to a compound of tone + noise than to a compound of tone + light. Experiment 2 included a comparison of these two compounds.

\section{Method}

The subjects were 102 male albino rats similar to those in Experiment 1 . They were housed and deprived as before.

The apparatus was unchanged except that a white-noise CS $(86 \mathrm{~dB}[\mathrm{C}])$ was provided by a Grason-Stadler noise generator (Model $455 \mathrm{C}$ ). The noise $(\mathrm{N})$ was played through a second speaker mounted on the box lid.

The procedure was that of Experiment 1 with the following exceptions. On the conditioning day, five groups of rats (TL+/TL, $\mathrm{TN}+/ \mathrm{TN}, \mathrm{T}+/ \mathrm{T}, \mathrm{N}+/ \mathrm{N}$, and $\mathrm{L}+/ \mathrm{L}$ ) received a $4-\sec$ simultaneous pairing of the CS and US, as in Experiment 1. The type of CS these groups received should be clear from the group names. Five other groups of rats received the 4-sec CS and the 4-sec US explicitly unpaired. For these EU groups (EUTL/TL, EUTN/TN, EUT/T, $\mathrm{EUN} / \mathrm{N}$, and EUL/L), the CS began $30 \mathrm{sec}$ into the 432 -sec session. The US began 3 min after CS termination. On the test day, the rats received the $\mathrm{CS}$ that they had experienced during conditioning.

The experiment was conducted in three replications, with each group represented in each replication. Groups $\mathrm{TL}+/ \mathrm{TL}$ and $\mathrm{TN}+/ \mathrm{TN}$ had 11 rats each; the rest had 10 each.

\section{Results and Discussion}

Lick suppression and freezing. The top panel of Figure 4 shows the mean log pre-CS and CS10 times to the test CS. The bottom panel shows the freezing during the first $30 \mathrm{sec}$ of that CS. The results suggest more suppression and freezing to the CSs that were paired with shock than to those that were explicitly unpaired. This suggestion was supported statistically.

The $\log$ CS10 times for groups trained and tested with an element (Groups T+/T, EUT/T, N+/N, EUN/N, L+/L, and EUL/L) were subjected to a $2 \times 3$, treatment (paired or $\mathrm{EU}) \times \mathrm{CS}(\mathrm{T}, \mathrm{N}$, or $\mathrm{L})$, ANOVA to see if simultaneous conditioning occurred to the element CSs. The main effect of treatment $[F(1,54)=12.20]$ provided evidence for such conditioning. The interaction between the two factors was not significant $(F<1)$, implying similar conditioned performance to each element. The main effect
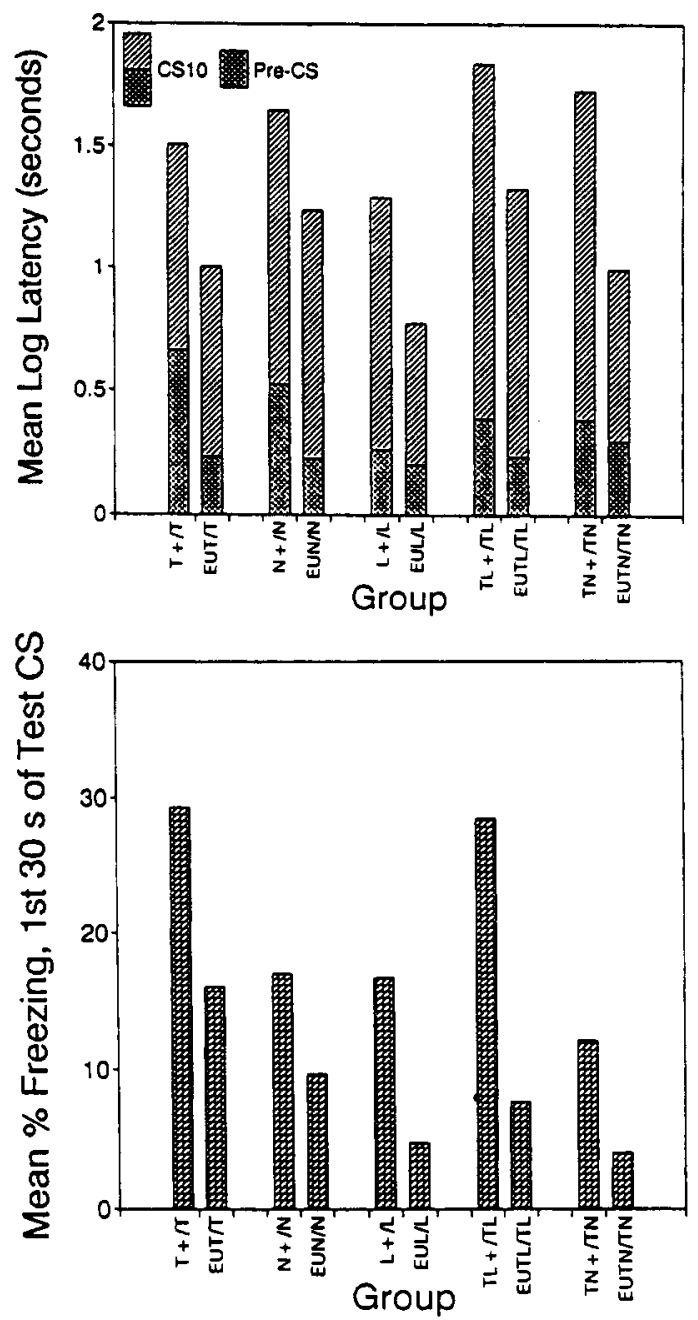

Figure 4. Experiment 2. Top panel: mean log pre-CS times (bottom part of bar) and mean log CS10 times (entire bar) during test CS. Bottom panel: mean percent of observations judged as freezing during the first 30 sec of test $\mathrm{CS}$.

of CS type approached significance $[F(2,54)=2.96$, $p=.06]$. Freezing during the first $30 \mathrm{sec}$ of the CS yielded similar results. Both the treatment effect $[F(1,54)=12.39]$ and the effect of CS type $[F(2,54)=5.53]$ were significant, but the CS type did not interact with treatment $(F<1)$, suggesting, again, similar levels of conditioning to each element.

The $\log$ CS 10 times for groups trained and tested with a compound (Groups TL+/TL, EUTL/TL, TN+/TN, and EUTN/TN) were subjected to a $2 \times 2$, treatment (paired or EU) $\times$ CS (TL or TN), ANOVA to see if simultaneous conditioning had occurred to the compounds. Only the main effect of treatment $[F(1,38)=17.46]$ was significant, providing evidence for such conditioning. For freezing during the first $30 \mathrm{sec}$ of the $\mathrm{CS}$, the main effect of treatment $[F(1,38)=12.74]$ likewise suggested simultaneous conditioning to the compound CSs. The main effect of $\mathrm{CS}[F(1,38)=6.10]$ indicated that $\mathrm{TL}$ 
evoked more freezing than did TN. Thus, the prediction that TN would evoke more freezing than TL was clearly not confirmed.

Two $2 \times 2$, treatment (paired or EU) $\times$ CS (element or compound), ANOVAs were conducted to see if conditioning was greater to the TL compound than to either element. The first ANOVA compared suppression to TL versus T (Groups TL+/TL, EUTL/TL, T+/T, and EUT/T). The second compared suppression to TL versus $L$ (Groups TL+/TL, EUTL/TL, L+/L, and EUL/L). Neither treatment $\times$ CS type interaction was significant $(F \mathrm{~S}<1)$, providing no support for the idea that conditioning with the TL compound was stronger than that to either element. Two similar $2 \times 2$, treatment $\times$ CS, ANOVAs were done to see if conditioning was greater to the TN compound than to either element. The first compared suppression to TN versus T (Groups TN+/TN, EUTN/TN, T+/T, and EUT/T). The second compared suppression to TN versus N (Groups $\mathrm{TN}+/ \mathrm{TN}, \mathrm{EUTN} / \mathrm{TN}, \mathrm{N}+/ \mathrm{N}$, and EUN/N). Again, neither treatment $\times$ CS type interaction was significant $[F \mathrm{~s}(1,37)$ $<1.26$ ], providing no evidence for stronger conditioning to a TN compound than to its elements. Similar ANOVAs on the freezing scores from the first $30 \mathrm{sec}$ of the CS also found no significant interactions $(F \mathrm{~s}<1.01)$, again providing no evidence for stronger conditioning to a compound than to an element.

An analysis of the log pre-CS times revealed a main effect of treatment $[F(1,92)=8.27]$, indicating that preCS times were significantly longer for rats that had the CS paired with the US than for rats that had the CS and US explicitly unpaired. Despite the lack of a significant treatment $\times \mathrm{CS}$ interaction $(F<1)$, we made comparisons to see if this was true for all of the stimuli. Only the difference in pre-CS times between the paired and explicitly unpaired tone reached significance $[t(18)=2.09]$. Although any correspondence between pre-CS and CS times is undesirable, the correspondence seen here appears more coincidental than causal. The size of the difference between experimental and control group performance on the pre-CS measure does not seem to covary with size of the difference on the performance on the CS measures.

Rearing. Figure 5 shows the mean percent rearing during the first $10 \mathrm{sec}$ of the test CS. As in Experiment 1 , there was some evidence that conditioned freezing suppressed rearing. The clearest case is the contrast between Groups TL+/TL and EUTL/TL $[t(19)=2.75]$. The compound was not conditioned in Group EUTL/TL, so the compound evoked much rearing. In Group TL+/TL, however, the compound was conditioned, and the freezing it evoked suppressed rearing.

The results with both the $\log$ CS10 times and freezing during the first $30 \mathrm{sec}$ of the CS provide evidence for simultaneous conditioning to $\mathrm{T}, \mathrm{N}$, and $\mathrm{L}$ elements and to the TL and TN compounds. However, despite the use of an appropriate (EU) control procedure and an appropriate statistical analysis, there was no evidence of stronger conditioning to a compound $\mathrm{CS}$ than to either element alone.

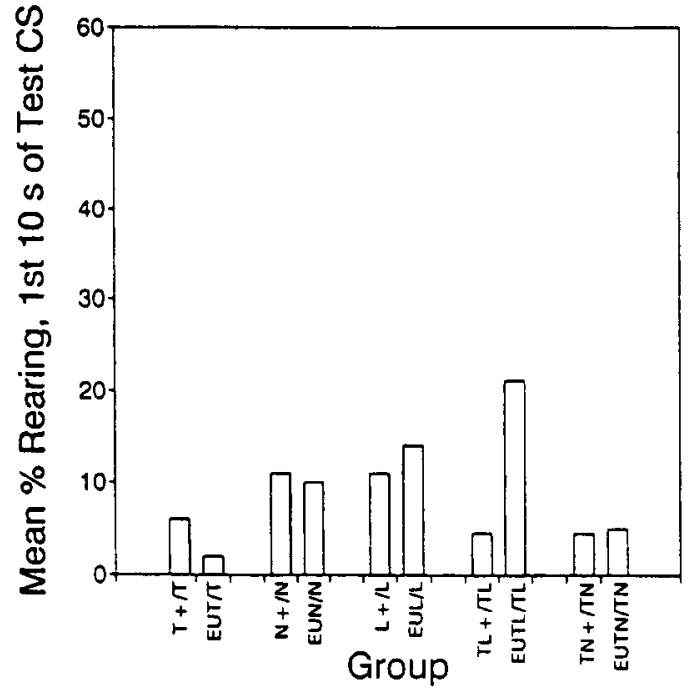

Figure 5. Mean percent of observations judged as rearing during the first $10 \mathrm{sec}$ of the test $C S$ in Experiment 2.

\section{EXPERIMENT 3}

Experiments 1 and 2 replicated and extended previous evidence for one-trial simultaneous fear conditioning but failed to strengthen it by using compound CSs. One possible reason for that failure is that forward trace conditioning occurred in the EU control groups. If so, then that conditioning could have been stronger to compounds than to elements, thus precluding a treatment $\times$ CS type interaction. Experiment 3 sought evidence for forward trace conditioning in the EU control procedure of Experiment 2. It did so by comparing the suppression and freezing in that control versus that in two other control procedures. One of these other procedures was a US-alone (USa) control. The second was an EU control in which the CS followed the US by a long trace interval. If forward trace conditioning occurred in the EU controls of Experiment 2, then suppression and freezing should be stronger in that control than in the two new controls. Experiment 3 also turned to the phenomenon of one-trial backward conditioning and sought to strengthen it by using CS compounds.

\section{Method}

The subjects were 74 male albino rats similar to those of Experiment 1 . They were housed and deprived as before. The apparatus was unchanged. The procedure was that of Experiment 1, with the following exceptions. On the conditioning day, all groups received a 4-sec US beginning $214 \mathrm{sec}$ into the $432-\mathrm{sec}$ session. Groups USa/T and USa/TL received only that US. Groups $+T / T$ and $+\mathrm{TL} / \mathrm{TL}$ received a 4-sec CS ( $\mathrm{T}$ or $\mathrm{TL}$, respectively) immediately after US termination. Four groups (EUFT/T, EUFTL/TL, EUBT/T, and EUBTL/T) received the CS and US explicitly unpaired. For the two EUF groups ( $\mathrm{F}$ for forward trace conditioning), the CS terminated 3 min before US onset, as in Experiment 2. For the two EUB groups (B for backward trace conditioning), the CS began 3 min after the US ended. The experiment was conducted in two replications with each group represented in each replication. Groups $+\mathrm{T} / \mathrm{T}$ and $+\mathrm{TL} / \mathrm{TL}$ had 10 rats each. The remaining groups had 9. 


\section{Results and Discussion}

Lick suppression and freezing. The top panel of Figure 6 shows the mean log pre-CS and CS10 times to the test CS. The bottom panel shows the freezing. The results suggest stronger suppression and freezing in the backward-paired groups than in some, but not all, of the control groups. There was no evidence for forward trace conditioning in the EUF controls. Indeed, surprisingly, the EUB control group tended to suppress and freeze more than did the other controls. These statements received some statistical support.

The data from the groups that received control treatments for conditioning to $T$ (Group USa/T, EUFT/T, and EUBT/T) were subjected to a one-way ANOVA to see if there was more suppression in Group EUFT/T, for which forward trace conditioning was conceivable, than in the other two control groups, for which forward trace conditioning was inconceivable. For the CS10 times, there were no differences among the groups $(F<1)$. For freez-
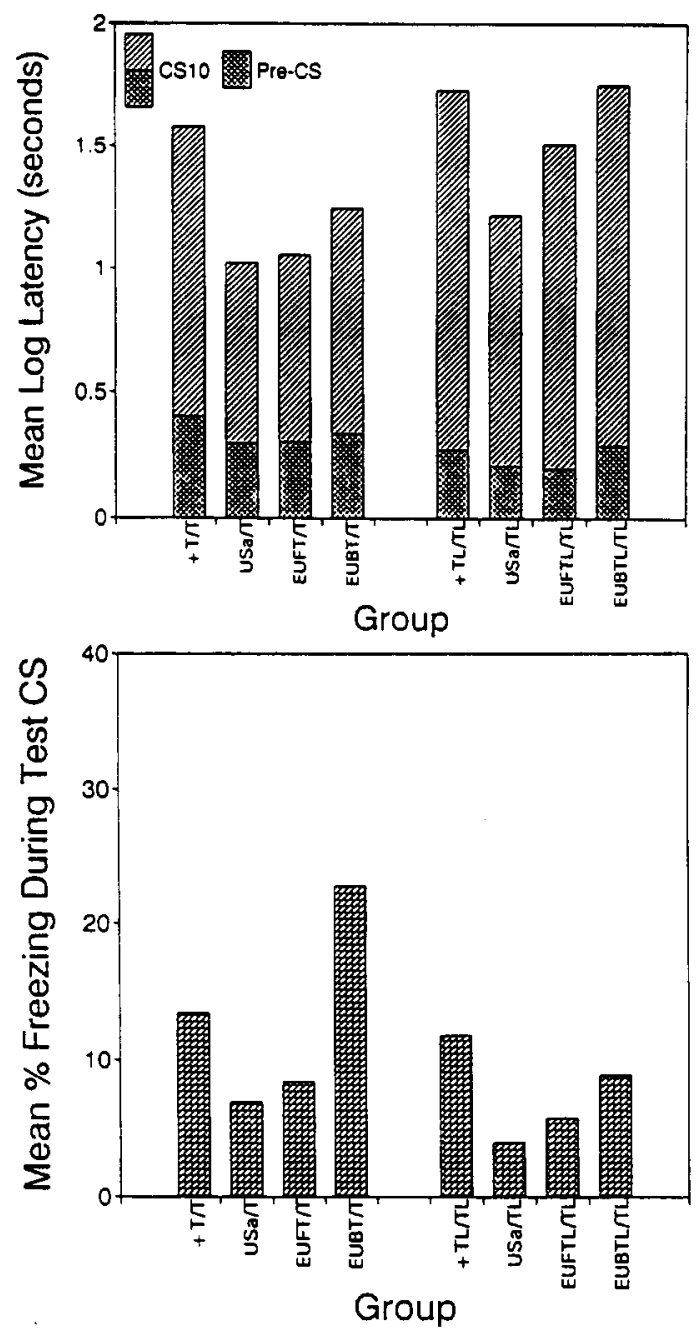

Figure 6. Experiment 3. Top panel: mean log pre-CS times (bottom part of bar) and mean log CS10 times (entire bar) during test CS. Bottom panel: mean percent of observations judged as freezing during test $\mathrm{CS}$. ing, group differences were significant $[F(2,24)=4.10]$, but comparisons showed that Group EUBT/T froze more than Groups USa/T and EUFT/T [ts $(16)>2]$. Thus, for both measures, there was no evidence for forward trace conditioning in Group EUFT/T. Indeed, it seemed that more conditioning occurred in Group EUBT/T.

A similar ANOVA on the data from the groups that received control treatments for conditioning to the compound (Groups USa/TL, EUFTL/TL, and EUBTL/TL) was also performed. For CS10 times, it found no differences among groups either for CS10 times $[F(2,24)=$ $2.94]$ or for freezing $(F<1)$. Clearly, neither measure suggested forward trace conditioning in Group EUFTL/TL. If anything, that group tended both to suppress and to freeze less than Group EUBTL/TL, for which forward trace conditioning was impossible.

Three $2 \times 2$, treatment (paired or control) $\times \mathrm{CS}(\mathrm{T}$ or TL), ANOVAs were done in search of evidence for backward conditioning and to see if conditioning was greater with the compound than with the tone element. The first ANOVA included the backward-paired groups and their US-alone controls (Groups +T/T, USa/T, +TL/TL, and $\mathrm{USa} / \mathrm{TL}$ ). The second included the backward-paired groups and their EUF controls (Groups $+\mathrm{T} / \mathrm{T}$, EUF/T, +TL/TL, and EUF/TL). The third included the backward-paired groups and their EUB controls (Groups $+\mathrm{T} / \mathrm{T}$, EUB/T, $+\mathrm{TL} / \mathrm{TL}$, and EUB/TL). For the CS10 times, the main effect of treatment was significant in the first two ANOVAs $[F \mathrm{~s}(1,34)>4.88]$, but not in the third $(F<1)$. So the analyses provided evidence for backward conditioning to $T$ and TL when the backward-paired rats were compared with the USa or EUF rats but not when compared with the EUB rats. The interaction between treatment and CS type was not significant in any of the ANOVAs $(F s<1)$, implying similar conditioning to TL and T. For freezing, the main effect of treatment was significant only in the first ANOVA $[F(1,34)=5.87]$. Thus, freezing provided evidence for backward excitatory conditioning to $\mathrm{T}$ and to $\mathrm{TL}$ only when the backward-paired rats were compared with the USa rats. The interaction between treatment (paired vs. control) and CS type (T vs. TL) was not significant in any of the ANOVAs. Thus, there was no evidence for stronger conditioning to a compound than to an element.

The differences in suppression discussed above were not complicated by differences in lick baselines. Analyses of the mean log pre-CS latencies comparable to those conducted on $\log$ CS 10 times revealed no differences among groups $(F \mathrm{~S}<1)$.

Rearing. Figure 7 shows the mean percent rearing during the first $10 \mathrm{sec}$ of the 2 -min test CS. Clearly, there was more rearing to the TL compound than to $\mathrm{T}[F(1,66)=$ 22.20], a result consistent with the findings of Experiment 1. And, as in Experiments 1 and 2, the data suggested that freezing suppresses rearing. For example, Group +TL/TL tended to rear less than Groups USa/TL and EUFTL/TL, but these differences were not significant. Group EUBTL/TL, which tended to freeze more than Groups USa/TL and EUF/TL also showed less rearing $[F \mathrm{~s}(1,66)>4.28]$. 


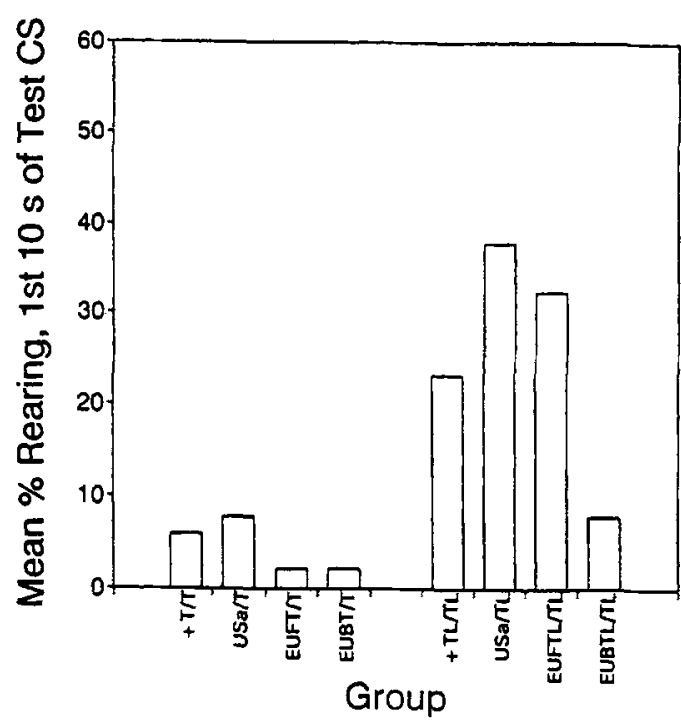

Figure 7. Mean percent of samples judged as rearing during the first 10 sec of the test CS in Experiment 3.

The results of Experiment 3 suggest that forward trace conditioning did not occur in the EU groups of Experiment 2 , and therefore that such conditioning cannot explain the absence of the treatment $\times$ CS type interaction needed to infer stronger conditioning to a compound versus its elements.

\section{GENERAL DISCUSSION}

The present experiments replicated previous evidence from this laboratory for one-trial excitatory simultaneous and backward conditioning (e.g., Ayres et al., 1987; Burkhardt \& Ayres, 1978; Mahoney \& Ayres, 1976; Shurtleff \& Ayres, 1981). The present work used a variety of CS elements and CS compounds (tone, light, noise, tone+light, and tone+noise). It also used a variety of measures of conditioning (suppression of licking, freezing, and-for the tone+light compound-the suppression of rearing evoked by the test CS). It used a number of control procedures for assessing conditioning (USalone, explicitly unpaired, and cross-modal, for example, Groups $\mathrm{T}+/ \mathrm{L}$ and $\mathrm{L}+/ \mathrm{T})$. This successful replication of evidence for one-trial simultaneous and backward conditioning is of note because of the mixed unpublished evidence for excitatory backward conditioning obtained recently in this laboratory, and because of the recent failures of other workers to find evidence for excitatory simultaneous or backward conditioning unless test procedures involved indirect measures or reminder cues (Barnet et al., 1991; Gordon et al., 1985; Matzel et al., 1988). Our results confirm that, although such test procedures may help to reveal conditioning due to simultaneous or backward pairing, they are not always necessary.

Although our attempt to replicate past work was successful, our attempt to enhance simultaneous and backward excitatory fear conditioning by using compound CSs instead of single elements was not. We failed in several efforts to produce more conditioning to a compound CS than to its elements. CS compounds did produce more suppression and freezing than did single elements for experimental groups, but the same was true in control groups. Therefore, we have no evidence that the stronger response in the experimental groups was due to a larger associative effect as opposed to a larger nonassociative one. Such evidence would have required a larger difference between experimental and control groups trained with CS compounds than between those trained with CS elements.

We considered the idea that this larger difference might not have occurred because there was some (weak) conditioning in the control groups. The use of compounds might enhance this weak conditioning in the controls just as it might enhance the stronger conditioning in the experimental groups. Such control group conditioning was conceivable at least in the EU controls of Experiment 2. For those controls, the CS ended 3 min before US onset, thus allowing remote forward trace conditioning. The results from the USa and EUB controls of Experiment 3, however, offered no support for that idea. Indeed, if conditioning occurred in any control procedure, it most likely occurred in the EUB control of Experiment 3. That control received the CS $3 \mathrm{~min}$ after US termination. Surely, the most surprising result of this research was the performance of that control. For both the T element and the TL compound, the EUB control tended to show more suppression and freezing than either of the other controls. The EUB control showed significantly more freezing to the $\mathrm{T}$ element than did either of the other two controls. And, although there was evidence for one-trial backward excitatory conditioning when the backwardpaired groups were compared with the USa and EUF controls, no such evidence was found when the backward-paired group was compared with the EUB control. The EUB control thus appears to be more conservative than either the USa or EUF controls.

Mahoney and Ayres (1976) included both EUF and EUB controls in their study and found no difference between them. Moreover, lick suppression in their EU groups appeared similar to that in a USa control. Their results suggested that the choice of control procedures was somewhat arbitrary, and, with one exception (see below), subsequent published work in this laboratory did not use the EUB control. On a priori grounds, the USa and EUF controls seemed most likely to be conservative. The USa control was presumed conservative because the test CS, being novel, should evoke ORs that would cause lick suppression. The EUF control was presumed conservative because it allowed the possibility of forward trace conditioning. The EUB control was presumed least conservative. Its test CS was not novel and therefore was less likely to evoke unconditioned suppression. Moreover, it could not acquire any excitatory value through a remote forward association, and indeed might acquire inhibitory value by being nonreinforced in a context made excitatory by the US (Rescorla \& Wagner, 1972). The results of Experiment 3 suggest that these lines of reasoning were misguided. Yet, because these results were unex- 
pected theoretically and because they differed from those of Mahoney and Ayres (1976), perhaps they reflect only a sampling error. This prospect drove us to reexamine the only other published report from this laboratory that included the EUB control procedure (Bevins \& Ayres, 1992a). There, the $\log$ CS10 times for EUB and EUF controls did not differ significantly and were pooled for comparison with a backward-paired condition. That comparison revealed significantly longer CS10 times in the backward-paired condition. Fortunately, the original ANOVA from that work was still on file, so we were able to use its error term to contrast the backward-paired condition against the EUF and EUB controls separately. These contrasts found that the backward-paired condition $(M=1.22)$ differed significantly $[t(80)=2.44]$ from the EUF control $(M=0.85)$ but not $(t<1)$ from the EUB control $(M=1.07)$. Thus, Bevins and Ayres's results agree with ours in suggesting that the EUB control is more conservative than the EUF control. In a more recent study, Bevins and Ayres (1992b) assigned 35 rats to each of the EUF and EUB conditions. The log CS10 times to the tone CS were found to be significantly longer in the EUB condition. Clearly, we do not believe that the present data pattern reflects a sampling error.

Although we were surprised to find that the EUB control was more conservative than the EUF control, that result is understandable in terms of second-order conditioning reinforced by context (Mowrer \& Aiken, 1954) or in terms of within-compound associations between the CS and contextual cues (Marlin, 1982). Those factors, of course, might affect not only the CS in the EUB procedure, but also the $\mathrm{CS}$ in the backward-paired procedure. It is therefore possible that the published evidence for one-trial backward excitatory conditioning is due to these factors and not to the temporal contiguity of CS and US. Mowrer and Aiken (1954) anticipated that possibility.

The present work succeeded in finding evidence for quantitative differences in freezing to tone and light, especially early in the CS. During the first $30 \mathrm{sec}$ of the test CS, rats that had tone paired with the US froze more than did rats that had light paired with the US. The level of freezing to tone and light was similar later in the CS probably because of within-trial extinction. The difference in freezing early in the CS probably does not reflect a difference in the conditioned value of light and tone, because analyses of $\log$ CS10 times showed that lick suppression to the two CSs was similar. This pattern of more freezing to tone than to light despite evidence for similar levels of conditioned value resembles that found by others (Ayres et al., 1985; Bevins \& Ayres, 1991; Helmstetter \& Fanselow, 1989; Kim et al., 1996; Sigmundi \& Bolles, 1983).

The greater freezing to tone than to light in the present work again raises the question of whether a unique defensive behavior to light exists. Light may evoke a conditioned defensive behavior (other than freezing) that, like freezing, can disrupt licking. Researchers have sug- gested that rearing is the unique behavior to light that accounts for the differences in freezing evoked by light and tone (Ayres et al., 1985; Helmstetter \& Fanselow, 1989). The present work identified rearing as an OR to light and suggested that rearing and freezing were mutually interfering. Therefore, we might hypothesize that the rearing $\mathrm{OR}$ interfered with the freezing $\mathrm{CR}$, and that rearing to light caused the weaker freezing to light versus tone. We should note, however, that, in previous work, tone evoked more freezing than did light long after ORs to light should have habituated (Ayres et al., 1985; Bevins \& Ayres, 1991, 1992c; Kim et al., 1996), and did so even when CSs were minutes long. Rearing ORs would presumably interfere with freezing only early in a CS. Thus, it seems that we need a unique conditioned defensive behavior to light, not a unique OR to light, to explain past results (Ayres et al., 1985; Bevins \& Ayres, 1991).

A detailed search of the videotaped behavior, however, failed to reveal a defensive behavior unique to light. For example, the rats did not paw at the floor, walls, or lid of the box as if trying to escape. They did not move to a certain area as if trying to withdraw from the light. Other than freezing, no behavior during the light appeared to be defensive. These findings agree with those of others who made thorough attempts to identify a unique defensive behavior to light yet failed to do so (Fanselow \& Lester, 1988).

When the present data were collected, the failure to find a defensive behavior unique to light was puzzling because tone evoked more freezing than light but similar levels of barpress and lick suppression. Subsequent study of barpress suppression, however, has shown that both cues evoke similar withdrawal from the bar (Bevins \& Ayres, 1992c). Such withdrawal could explain the similarity of suppression despite the difference in freezing.

\section{REFERENCES}

AlBert, M. (1990). Conditioning to a compound CS and the observation of CS-elicited behavior in I-trial simultaneous and 1-trial backward conditioning procedures. Unpublished doctoral dissertation, University of Massachusetts, Amherst.

Ayres, J. J. B., Axelrod, H., Mercker, E., Muchnik, F., \& Vigorito, M. (1985). Concurrent observations of barpress suppression and freezing: Effects of CS modality and on-line vs. off-line training upon posttrial behavior. Animal Learning \& Behavior, 13, 44-50.

Ayres, J. J. B., Haddad, C., \& Albert, M. (1987). One-trial excitatory backward conditioning as assessed by conditioned suppression of licking in rats: Concurrent observations of lick suppression and defensive behaviors. Animal Learning \& Behavior, 15, 212-217.

Barnet, R. C., Arnold, H. M., \& Miller, R. R. (1991). Simultaneous conditioning demonstrated in second-order conditioning: Evidence for similar associative structure in forward and simultaneous conditioning. Learning \& Motivation, 22, 253-268.

Bevins, R. A., \& Ayres, J. J. B. (1991). Two issues in Pavlovian fear conditioning: Selective fear of bright vs. dark, and CS determinants of CR form. Behavioural Processes, 24, 211-218.

Bevins, R. A., \& Ayres, J. J. B. (1992a). One-trial backward excitatory fear conditioning transfers across contexts. Behaviour Research $\&$ Therapy, 30, 551-554.

Bevins, R. A., \& Ayres, J. J. B. (1992b). [One-trial fear conditioning in forward versus backward explicitly unpaired control procedures]. Unpublished raw data. 
Bevins, R. A., \& Ayres, J. J. B. (1992c). Rats' location during conditioned suppression training. Animal Learning \& Behavior, 20, 8-16.

BURKHARDT, P. E., \& AYRES, J. J. B. (1978). CS and US duration effects in one-trial simultaneous fear conditioning as assessed by conditioned suppression of licking in rats. Animal Learning \& Behavior, 6, 225-230.

DOMJAN, M., \& BURKHARD, B. (1986). The principles of learning and behavior (2nd ed.). Monterey, CA: Brooks/Cole.

FANSELOW, M. S., \& LESTER, L. S. (1988). A functional behavioristic approach to aversively motivated behavior: Predatory imminence as a determinant of the topography of defensive behavior. In R. C. Bolles \& M. D. Beecher (Eds.), Evolution and learning (pp. 185212). Hillsdale, NJ: Erlbaum.

Gordon, W. C., McGinnis, C. M., \& Weaver, M. S. (1985). The effect of cuing after backward conditioning trials. Learning \& Motivation, 16, 444-463.

GoRMEZANO, I. (1972). Investigations of defense and reward conditioning in the rabbit. In A. H. Black \& W. F. Prokasy (Eds.), Classical conditioning II: Current research and theory (pp. 151-181). New York: Appleton-Century-Crofts.

Helmstetter, F. J., \& FANSELOW, M. S. (1989). Differential secondorder aversive conditioning using contextual stimuli. Animal Learning \& Behavior, 17, 205-212.

HOFFMAN, H. S., \& FlESHLER, M. (1962). A relay sequencing device for scrambling grid shock. Journal of the Experimental Analysis of Behavior, 5, 329-330.

Holland, P. C. (1979). The effects of qualitative and quantitative variation in the US on individual components of Pavlovian appetitive conditioned behavior in rats. Animal Learning \& Behavior, 7, 424-432.

KAMIN, L. J. (1968). "Attention-like" processes in classical conditioning. In M. R. Jones (Ed.), Miami symposium on the prediction of behavior, 1967: Aversive stimulation (pp. 9-31). Coral Gables, FL: University of Miami Press.

Kasprow, W. J., Schachtman, T. R., \& Miller, R. R. (1987). The comparator hypothesis of conditioned response generation: Manifest conditioned excitation and inhibition as a function of relative excitatory strengths of CS and conditioning context at the time of testing. Journal of Experimental Psychology: Animal Behavior Processes, $13,395-406$

KIM, S. D., Rivers, S., Bevins, R. A., \& AYres, J. J. B. (1996). Conditioned stimulus determinants of conditioned response form in Pavlovian fear conditioning. Journal of Experimental Psychology: Animal Behavior Processes, 22, 87-104.
Mahoney, W. J., \& AYres, J. J. B. (1976). One-trial simultaneous and backward fear conditioning as reflected in conditioned suppression of licking in rats. Animal Learning \& Behavior, 4, 357-362.

MARLIN, N. A. (1982). Within-compound associations between the context and the conditioned stimulus. Learning \& Motivation, 13, 526-541.

Matzel, L. D., Held, F. P., \& Miller, R. R. (1988). Information and expression of simultaneous and backward associations: Implications for contiguity theory. Learning \& Motivation, 19, 317-344.

MOWRER, O. H., \& AIKEN, E. G. (1954). Contiguity vs. drive-reduction in conditioned fear: Temporal variations in conditioned and unconditioned stimulus. American Journal of Psychology, 67, 26-38.

Rescorla, R. A., \& WAGNER, A. R. (1972). A theory of Pavlovian conditioning: Variations in the effectiveness of reinforcement and nonreinforcement. In A. H. Black \& W. F. Prokasy (Eds.), Classical conditioning II: Current research and theory (pp. 64-99). New York: Appleton-Century-Crofts.

ShURTLEF, D., \& AYREs, J. J. B. (1981). One-trial backward excitatory fear conditioning in rats: Acquisition, retention, extinction, and spontaneous recovery. Animal Learning \& Behavior, 9, 65-74.

SigmuNDI, R. A., \& Bolles, R. C. (1983). CS modality, context conditioning, and conditioned freezing. Animal Learning \& Behavior, 11, 205-212.

StGmund, R. A., Bouton, M. E., \& Bolles, R. C. (1980). Conditioned freezing in the rat as a function of shock intensity and CS modality. Bulletin of the Psychonomic Society, 15, 254-256.

SPetch, M. L., Wilkie, D. M., \& Pinel, J. P. J. (1981). Backward conditioning: A reevaluation of the empirical evidence. Psychological Bulletin, 89, 163-175.

van Willigen, F., Emmett, J., Cote, D., \& Ayres, J. J. B. (1987). CS modality effects in one-trial backward and forward excitatory conditioning as assessed by conditioned suppression of licking in rats. $A n$ imal Learning \& Behavior, 15, 201-211.

\section{NOTE}

1. Because of the small number of rats per group in each replication, the replications factor was not included in any of the data analyses in this paper.

(Manuscript received November 7, 1994; revision accepted for publication July 19,1996 .) 